\title{
Comparative study of the FAOS and FAAM questionnaires as functional assessment instruments for patients with hallux valgus
}

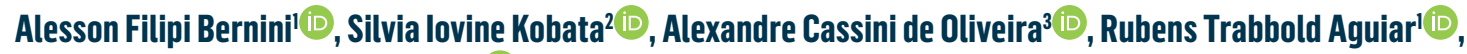 \\ Antônio César Mezêncio Da Silveira' [D
}

1. Instituto de Previdência dos Servidores do Estado de Minas Gerais, Belo Horizonte, MG, Brazil.

2. Hospital Life Center, Belo Horizonte, MG, Brazil.

3. Hospital das Clínicas da Universidade Federal de Minas Gerais, Belo Horizonte, MG, Brazil.

\begin{abstract}
Objective: To compare the Portuguese translations of the Foot and Ankle Activity Measure (FAAM) and the Foot and Ankle Outcome Score (FAOS) questionnaires as functional assessment instruments for patients with hallux valgus and assess correlations between scores and severity of deformity.
\end{abstract}

Methods: A total of 28 patients were assessed and the functional scores provided by the FAAM and FAOS questionnaires were compared and their correlations with clinical and radiological severity were analyzed.

Results: Mean age was 46.88 years (range: 18 to 64 ). Laterality was distributed as follows: $57.1 \%$ had the deformity on the right foot ( 16 cases) and $42.9 \%$ on the left (12 cases). The deformities identified were graded as follows: $26.1 \%$ of patients had mild deformity ( 6 cases), $45.3 \%$ had moderate deformity (14 cases), and $28.6 \%$ had severe deformity ( 8 cases). It was observed that the distribution of scores for the different grades of deformity was the same for both questionnaires.

Conclusion: There was no significant difference between the results obtained using the FAAM or the FAOS questionnaire or in the relationship of proportionality between radiological deformity grade and the functional scores obtained using the two tests.

Level of Evidence IV; Therapeutic Studies; Case Series.

Keywords: Hallux valgus; Diseases of the foot; Surveys and questionnaires.

\section{Introduction}

Hallux valgus, known popularly as bunion, is a complex disorder of the first ray of the foot that is often seen in conjunction with deformities and symptoms involving the smaller toes $^{(1,2)}$. The pathophysiology of this deformity is related to extrinsic factors (footwear, trauma) and intrinsic factors (pes planovalgus, hypermobility of the first metatarsal-cuneiform joint, short or varus first metatarsal, ligamentous laxity, or an inclined hallux interphalangeal joint)(3).

The prevalence of this deformity varies from 23 to $64.7 \%$ in the general population and clinical presentation can include pain, deformity, and limitations to wearing footwear, which can interfere with daily activities and sports ${ }^{(4-9)}$. A recent po- pulation based study demonstrated that $76.8 \%$ of patients with hallux valgus have painful feet, compared with $6.5 \%$ of the population without deformities ${ }^{(4)}$.

Studies have compared the questionnaires often used in the international literature on a range of orthopedic diseases, assessing their methodological quality and evidence level, and showing that the Foot and Ankle Outcome Score (FAOS) and the Foot and Ankle Ability Measure (FAAM) questionnaires are frequently used and have comparable validity to the Short Form Health Survey (SF-36). Use of questionnaires in orthopedic practice has increased considerably, both to assess patient satisfaction with the results within health services and as a method for comparing different surgical approaches ${ }^{(10-14)}$.
Study performed at the Hospital LifeCenter, Belo Horizonte, MG, Brazil.

Correspondence: Alesson Filipi Bernini. 772 Dos Otoni St., Santa Efigênia, Belo Horizonte, MG, Brazil, Zip Code: 30150-270. E-mail: af_bernini@yahoo.com.br Conflicts of interest: none. Source of funding: none. Date received: March 31 , 2020. Date accepted: July 10, 2020. Online: August 30, 2020.
How to cite this article: Bernini AF, Kobata SI, Oliveira AC, Aguiar RT, Silveira ACM. Comparative study of the FAOS and FAAM questionnaires as

functional assessment instruments for patients with hallux valgus. J Foot Ankle. 2020;14(2):144-7. 
There are several questionnaires in the specialist literature on diseases of the foot and ankle for assessing the functional results after patients have undergone surgical treatment. The choice of functional assessment method should take into consideration use of questionnaires that have been validated in both the original language and in the version translated into the patients' native language ${ }^{(11,12)}$.

However, there is no consensus on which questionnaire is the best for functional assessment of hallux valgus patients or whether translation of these questionnaires into Portuguese may have interfered with comparison of their results, preventing comparison of the results of different studies focused on the same condition ${ }^{(13)}$.

A recent study demonstrated that $83 \%$ of surgeons use questionnaires for routine assessments, for research, and for keeping records for quality control(13). However, there is a lack of published data to show whether the different questionnaires employed agree with other when used to assess patients with deformities of the forefoot.

The objective of this study is to compare the Portuguese translations of the FAAM and FAOS questionnaires as instruments for functional assessment of patients with hallux valgus and test whether their scores correlate with the severity of deformity assessed radiologically.

\section{Methods}

This study was approved by the Institutional Review Board and registered on the Plataforma Brasil database under CAAE (Ethics Evaluation Submission Certificate) number: 16913018.9.0000.5126.

After each patient had been informed about the objectives of the study and given their consent, the "Foot and Ankle Ability Measure" (FAAM) and the "Foot And Ankle Outcome Score" (FAOS) questionnaires were administered and physical examinations and radiographic assessments were conducted ${ }^{(14)}$.

Patients were recruited who were over the age of 18 years, female, had hallux valgus and no other disorders of the forefoot, agreed to take part, and signed free and informed consent.

All patients were assessed from 2011 to 2016, consecutively, by the same surgeon, and their demographic, clinical, and radiographic data and FAOS and FAAM functional scores were analyzed. Hallux valgus deformities were classified as mild, moderate, or severe according to the Coughlin classification $^{(2)}$. This classification takes into consideration the valgus angle of the hallux (AVH) and the intermetatarsal angle (IMA) between the first and second rays, measured on orthostatic $X$-rays taken in the dorsoplantar view. Measurements were taken by tracing lines and measuring the angles between them using X-ray image analysis software. The same researcher measured angles on all $X$-rays and the results were verified by a second evaluator at a later date.

Cases in which the AVH was less than 20 degrees and the IMA was between 9 and 11 degrees were classified as mild. Deformities with an $\mathrm{AVH}$ from 20 to 40 degrees and an IMA from 12 to 15 degrees were classified as moderate. Cases with an AVH exceeding 40 degrees and an IMA exceeding 16 degrees were classified as severe.

Inclusion criteria were adult, female patients whose only complaint was a bunion, with no other deformities of the forefoot, confirmed by clinical and radiographic examination. Exclusion criteria were age over 65 years, skeletal immaturity, chronic diseases such as cardiac and vascular diseases, which could influence physical activity, making them confounding factors by selecting patients with preexisting limitations of sporting functional capacity, and patients who were professional or semiprofessional sportswomen. Male patients and professional or semiprofessional sportswomen were excluded in order to avoid introducing selection bias by comparing the impact of the deformity on physical activity across different sexes or between patients with different levels of sporting ability.

\section{Sample size and statistical analysis}

The sample size was calculated on the basis of a two-tailed test, with 5\% significance level, 95\% confidence level, and $80 \%$ test power. The resulting sample size was 24 individuals. After accounting for an expected $15 \%$ loss from the sample, a sample size of 28 individuals was defined.

Statistical analysis of the data was conducted using SPSS (IBM) to conduct Student's $t$ tests and compare the questionnaire scores using variance tests and the Wilcoxon signed-rank test. For the categorical variables, descriptive statistics were calculated, expressing variables as frequencies and percentages with a 95\% confidence interval for the FAOS and FAAM questionnaires. Scores were also compared using the Wilcoxon signed-rank test and correlations between scores were estimated. The confidence level was defined as 0.05 .

\section{Results}

Twenty-eight female patients with hallux valgus were assessed clinically and functional assessment scores were calculated by administration of the FAAM and FAOS, with help from the researcher. Mean age was 47 years (range: 18 to 64 ) (Table 1).

Laterality was distributed as follows: $57.1 \%$ had the deformity on the right foot ( 16 cases) and $42.9 \%$ on the left ( 12 cases). The grades of deformity identified were as follows: $26.1 \%$ of patients had mild deformity ( 6 cases), $45.3 \%$ had moderate deformity (14 cases), and $28.6 \%$ had severe deformity (8 cases).

Table 1. Paired correlations

\begin{tabular}{lcccc} 
& & N & Correlation & Sig. \\
\hline Pair 1 & FAAM \& FAOS & 28 & 0.439 & 0.019 \\
Pair 2 & FAAM \& deformity & 28 & -0.058 & 0.771 \\
Pair 3 & FAOS \& deformity & 28 & -0.232 & 0.234 \\
\hline $\begin{array}{l}\text { Paired correlation tests demonstrating absence of significant difference between the scores ob- } \\
\text { tained using the FAAM and FAOS questionnaires }(p=0.19) \text { and absence of significant correlation } \\
\text { between the scores and severity of hallux valgus deformity }(p>0.05) .\end{array}$
\end{tabular}


Mean preoperative FAAM scores were 59.5 in the group of patients with mild deformity, 46.3 in the moderate group, and 48.25 in the severe group, while late postoperative scores were 84 for the mild, 82 for the moderate, and 84 for the severe groups.

No significant relationship was observed between radiographic severity of hallux valgus and functional limitation measured by this questionnaire, according to the Mann Whitney test $(p=1)$.

Mean preoperative FAOS scores were 89.17 in the group of patients with mild deformity, 74.4 in the moderate group, and 71.5 in the severe group, while postoperative scores were 99.5 in the mild, 98 in the moderate, and 99.5 in the severe groups.

No significant relationship was observed between radiographic severity of hallux valgus and functional limitation measured by this questionnaire, according to the Mann Whitney test $(p=0.182)$.

After testing correlations, we observed that there was no significant difference between scores using the FAAM or the FAOS questionnaire in relation to degree of hallux valgus deformity $(p=0.19)$ (Table 2$)$.

\section{Discussion}

The FAOS and FAAM questionnaires have both been translated and cross-culturally adapted ${ }^{(14)}$. However, these questionnaires are very often used in patients with different types of

Table 2. Frequency by age

\begin{tabular}{|c|c|c|c|c|c|}
\hline & & Frequency & Percent & $\begin{array}{l}\text { Valid } \\
\text { Percent }\end{array}$ & $\begin{array}{c}\text { Cumulative } \\
\text { Percent }\end{array}$ \\
\hline \multirow[t]{21}{*}{ Valid } & 18 & 1 & 3.6 & 3.6 & 3.6 \\
\hline & 23 & 1 & 3.6 & 3.6 & 7.1 \\
\hline & 26 & 1 & 3.6 & 3.6 & 10.7 \\
\hline & 27 & 1 & 3.6 & 3.6 & 14.3 \\
\hline & 34 & 1 & 3.6 & 3.6 & 17.9 \\
\hline & 35 & 2 & 7.1 & 7.1 & 25.0 \\
\hline & 36 & 1 & 3.6 & 3.6 & 28.6 \\
\hline & 38 & 1 & 3.6 & 3.6 & 32.1 \\
\hline & 39 & 3 & 10.7 & 10.7 & 42.9 \\
\hline & 41 & 1 & 3.6 & 3.6 & 46.4 \\
\hline & 47 & 1 & 3.6 & 3.6 & 50.0 \\
\hline & 54 & 1 & 3.6 & 3.6 & 53.6 \\
\hline & 55 & 1 & 3.6 & 3.6 & 57.1 \\
\hline & 56 & 1 & 3.6 & 3.6 & 60.7 \\
\hline & 58 & 3 & 10.7 & 10.7 & 71.4 \\
\hline & 60 & 2 & 7.1 & 7.1 & 78.6 \\
\hline & 61 & 1 & 3.6 & 3.6 & 82.1 \\
\hline & 62 & 2 & 7.1 & 7.1 & 89.3 \\
\hline & 63 & 1 & 3.6 & 3.6 & 92.9 \\
\hline & 64 & 2 & 7.1 & 7.1 & 100.0 \\
\hline & Total & 28 & 100.0 & 100.0 & \\
\hline
\end{tabular}

Frequency distribution of hallux valgus pathology by age. diseases, which impacts on interpretation of the results observed and their applicability in relation to specific disorders of the foot and ankle that have high prevalence in the population.

To date, there is no functional assessment questionnaire specifically for deformities of the forefoot, making it difficult to compare functional results between studies that use the different questionnaires validated in Portuguese, even when they study the same disorder. There is not yet any consensus on the impact of forefoot deformities in terms of limitations to activities of daily life and sports.

The Foot And Ankle Outcome Score questionnaire (FAOS) was created by adapting the Knee Injury and Osteoarthritis Outcome (KOOS) questionnaire and was developed to provide an instrument to assess functional limitations in different conditions of the foot and the ankle ${ }^{(15)}$. It comprises 42 items that cover presence of pain and a range of different symptoms, and daily activities, recreational activities, and sporting activities. Each item has a multiple-choice five-point Likert response scale ${ }^{(16)}$. The sum of the item scores is then transformed to a scale from 0 (worst result) to 100 (best result).

The Foot and Ankle Ability Measure questionnaire (FAAM) was developed to be a self-report questionnaire completed by the patient ${ }^{(17)}$, but studies conducted with the Portuguese version have administered the questionnaire with the patient helped by the researcher. It was designed to be used for functional assessment in different diseases of the foot and ankle. Items are answered on five-point Likert scales and are split into two sub-scales, one covering activities of daily living (21 items) and the other covering sporting activities ( 8 items). The sum of the item scores is transformed to a scale from 0 (worst function) to 100 (best result). There is also a supplement that assesses overall functional status from 0 to 100.

This study did not find significant differences between the FAAM and FAOS questionnaires when used as tools for assessment of the functional limitations perceived by patients with hallux valgus deformity. The functional results using the FAAM and FAOS questionnaires do not appear to have a significant relationship of proportionality with radiographic severity of the deformity, regardless of which questionnaire is used (FAAM $p=1.000$, FAOS $p=0.182$ ).

More studies should be conducted to investigate the level of agreement between widely-used questionnaires, investigating the most frequently treated diseases individually in order to improve reliability of comparison of results. One of the limitations of this study is its restriction of the sample to adult female patients. Other studies could test whether results are similar with elderly and male populations. Another limitation is the sample size and significant differences might be detected if the number of patients studied is increased.

\section{Conclusion}

No significant differences were observed in terms of the functional limitations perceived by patients with hallux valgus deformity using the FAAM or the FAOS questionnaires.

There was no significant relationship of proportionality between radiographic deformity grade and scores on the FAAM and FAOS questionnaires. 
Authors' contributions: Each author contributed individually and significantly to the development of this article: AFB *(https://orcid.org/O000-0001-97519738) conceived and planned the activities that led to the study, wrote the article, participated in the review process, approved the final version; ACO *(https://orcid.org/0000-0002-3477-830X) conceived and planned the activities that led to the study, wrote the article, participated in the review process, approved the final version; RTA *(https://orcid.org/0000-0003-1575-6057) wrote the article, participated in the review process, approved the final version; SIK *(https://orcid.org/0000-0002-9079-6940) wrote the article, participated in the review process, approved the final version; ACMS *(https://orcid. org/O00-0003-2013-7971) participated in the review process, approved the final version. *ORCID (Open Researcher and Contributor ID) (iD).

\section{References}

1. Canale ST, Beaty JH (editors). Campbel. Cirurgia Ortopédica. 12 ed. Rio de Janeiro: Elsevier; 2017.

2. Coughlin MJ, Saltzman C, Anderson RB (editors). Mann's surgery of the foot and ankle. 9 ed. Philadelphia: Elsevier; 2014.

3. Hebert S, Filho TEPB, Xavier R, Pardini Jr AG. Ortopedia e traumatologia: princípios e prática. 4 ed. Porto Alegre: Artmed; 2009.

4. Cho NH, Kim S, Kwon DJ, Kim HA. The prevalence of hallux valgus and its association with foot pain and function in a rural Korean community. J Bone Joint Surg Br. 2009;91(4):494-8.

5. Nix S, Smith M, Vicenzino B. Prevalence of hallux valgus in the general population: a systematic review and meta-analysis. J Foot Ankle Res. 201027;3:21

6. MacMahon A, Karbassi J, Burket JC, Elliott AJ, Levine DS, Roberts MM, Deland JT, O'Malley MJ, Yu J, Mancuso CA, Ellis SJ. Return to sports and physical activities after the modified lapidus procedure for hallux valgus in young patients. Foot Ankle Int. 2016;37(4):378-85.

7. Coughlin MJ, Jones CP. Hallux valgus: demographics, etiology, and radiographic assessment. Foot Ankle Int. 2007;28(7):759-77.

8. Nery C, Oliveira AC, Réssio C, Faria RG. Técnica da osteotomia de Scarf para correção do hálux valgo. Rev ABTPé. 2007;1(2):63-71.

9. Kristen $\mathrm{KH}$, Berger C, Stelzig S, Thalhammer E, Posch M, Engel A. The SCARF osteotomy for the correction of hallux valgus deformities. Foot Ankle Int. 2002;23(3):221-9.

10. Schrier JC, Palmen LN, Verheyen CC, Jansen J, Koëter S. Patientreported outcome measures in hallux valgus surgery. A review of literature. Foot Ankle Surg. 2015;21(1):11-5.
11. Mizusaki Al, Peccin MS, Rodrigues R, Mizusaki JM. Traducao e validacao do questionario FAOS - Foot and Ankle Outcome Score para lingua portuguesa. Acta Ortop Bras. 2009;17(4):232-5.

12. Arunakul M, Arunakul P, Suesiritumrong C, Angthong C, Chernchujit B. Validity and Reliability of Thai Version of the Foot and Ankle Ability Measure (FAAM) Subjective Form. J Med Assoc Thai. 2015; 98(6):561-7.

13. Sierevelt IN, Zwiers R, Schats W, Haverkamp D, Terwee CB, Nolte PA, Kerkhoffs GMMJ. Measurement properties of the most commonly used Foot- and Ankle-Specific Questionnaires: the FFI, FAOS and FAAM. A systematic review. Knee Surg Sports Traumatol Arthrosc. 2018;26(7):2059-73.

14. Moreira TS. Tradução e Adaptação Transcultural do Questionário Foot And Ankle Ability Measure Para o Português do Brasil [dissertação]. Belo Horizonte: Universidade Federal de Minas Gerais; 2012.

15. Roos EM, Roos HP, Lohmander LS, Ekdahl C, Beynnon BD. Knee Injury and Osteoarthritis Outcome Score (KOOS)--development of a self-administered outcome measure. J Orthop Sports Phys Ther. 1998;28(2):88-96.

16. Bermudes WR, Santana BT, Braga JHO, Souza PH. Tipos de escalas utilizadas em pesquisas e suas aplicações. Rev Vértices. 2016; 18(2):7-20.

17. Martin RL, Irrgang JJ, Burdett RG, Conti SF, Van Swearingen JM. Evidence of validity for the Foot and Ankle Ability Measure (FAAM). Foot Ankle Int. 2005;26(11):968-83. 